This item was submitted to Loughborough's Research Repository by the author.

Items in Figshare are protected by copyright, with all rights reserved, unless otherwise indicated.

Foiling the free riders: early experience with compulsory peer assessment at an online business school

PLEASE CITE THE PUBLISHED VERSION

PUBLISHER

(c) Loughborough University

LICENCE

CC BY-NC-ND 4.0

REPOSITORY RECORD

Williams, Jeremy B.. 2019. "Foiling the Free Riders: Early Experience with Compulsory Peer Assessment at an Online Business School”. figshare. https://hdl.handle.net/2134/2011. 
FOILING THE FREE RIDERS: EARLY EXPERIENCE WITH COMPULSORY PEER ASSESSMENT AT AN ONLINE BUSINESS SCHOOL

Jeremy B. Williams 



\title{
Foiling the Free Riders: Early Experience with Compulsory Peer Assessment at an Online Business School
}

\author{
Jeremy B. Williams \\ Director, Pedagogy and Assessment \\ Universitas 21 Global \\ http://www.u21global.com \\ jeremy@u21global.com \\ +65 64101324
}

\begin{abstract}
Getting students to work in teams is a tried and tested mechanism for promoting active learning (Kadel \& Keehner 1994). Team work, and the ability to work in teams, is also becoming increasingly valued in the world of business and commerce (Senge 1990). The question is: to what extent should assessment be tied to the collaborative efforts of teams? Generally speaking, opinion seems to be divided among those students who hate it and those who think it is extremely valuable. Those who find it a chore invariably complain about difficult personalities and those who 'free ride' off the efforts of others. This, of course, is no different to life in the real world and one might argue, therefore, that it is an authentic learning experience! A counter-argument is that, in the real world, there is also likely to be a reporting system within an organisation whereby the difficult and the lazy people are prevented from prospering beyond the short term. This paper reports on the first 12 months' experience of a compulsory peer assessment system that represents a modest attempt to install such a reporting system, with the goal of calling the free-riders to account. It details the implementation process, teething problems, successes to date, and future research plans.
\end{abstract}

\section{Introduction}

Working in teams has become a common feature of modern workplaces (Senge 1990). As a result, many tertiary institutions have sought to develop this particular generic skill among their graduates. Aside from its perceived value in the world of business and commerce, there appears to be little argument about the value of working in teams from a pedagogical point of view because of the benefits that accrue from peer learning (Kadel \& Keehner 1994). The assessment of team work, on the other hand, has generated a deal of controversy (see, for example, Conway, Kember, Sivan \& Wu, 1993; Lejk, Wyvill \& Farrow, 1996; Pitt, 2000). The fact remains, however, that if it is clear that there is value in peer learning, and tertiary courses include learning 
objectives about students' ability to work as part of a team, then there has to be some effective means of assessing teamwork (Cheng \& Warren 2000).

\section{The context}

Universitas 21 Global (U21G) is a completely online graduate school backed by 16 universities from around the world (including the universities of Birmingham, Edinburgh, Glasgow and Nottingham). In early 2004, students submitted their views on the assessment of team assignments (a key element of the MBA programme assessment regime) in a telephone survey and student focus group interviews conducted during the annual 'climate survey'. The overwhelming majority stated that any mechanism to thwart free-riders would be welcomed. Thus, commencing in April 2004, an online peer assessment tool was introduced that was based on a tried and tested instrument developed by the University of Technology, Sydney (UTS) called 'SPARK' (Freeman \& McKenzie, 2002), a tool which itself draws upon on a well-designed and validated paper-based peer assessment system developed by Goldfinch (1994).

Using the U21G model, students rate one another's (and their own) contribution to a team assignment on a 7-point scale where 0 is 'no contribution' and 5 is 'outstanding contribution', and where -1 can be awarded for being 'a hindrance to the team'. This they do according to a number of predetermined criteria; viz. collection of data, data analysis, co-ordination and writing of submission, overall quality of input (creative ideas, insights), and overall contribution to the efficient functioning of the team (see Figure 1).

Criteria

1 Collection of data

2 Data analysis

3 Co-ordination and writing of submission

4 Overall quality of input (creative ideas, insights)

5 Overall contribution to the efficient functioning of the team

\section{Self Lily Koh}
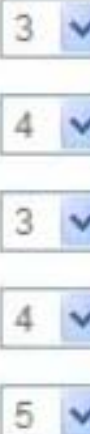

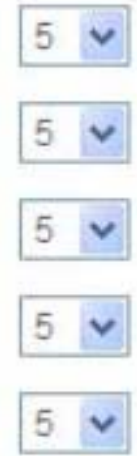

Arjun Singh

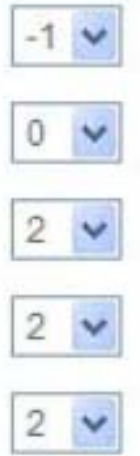

Figure 1. Student self and peer ratings

Unlike UTS, peer assessment at U21G is mandatory for all team assignments. Students have up to three days after they have submitted their assignment to submit peer assessments. On the fourth day after the assignment submission date, non-participation in the peer assessment process is treated as non-participation in the assignment itself. This means that the non-participating student will receive an individual score of zero, irrespective of the score awarded to the team. Importantly, in the event a team member does not participate in the peer assessment process, they are 
automatically taken out of the equation and the peer assessed score is determined by those that did participate.

\section{The SPA factor}

Those students who do take part have their individual scores revised in accordance with the SPA factor (Self and Peer Assessment factor). The SPA factor is calculated by taking the ratio of the sum of an individual's scores relative to the average sum of scores awarded to all other team members. For example, if an individual has a SPA factor of 0.83 , a team score of $80 \%$ will become $66 \%$ for that individual. Someone in the same team getting a SPA factor of 1.02 , on the other hand, will receive the individual score of $82 \%$, or $90 \%$ if their SPA factor is 1.12 (see Figure 2).

\begin{tabular}{|c|c|c|c|c|c|c|}
\hline & $\begin{array}{l}\text { Team } \\
\text { Name }\end{array}$ & Submitted Assignment & Submitted Date & Marks(\%) & $\begin{array}{c}\text { SPA } \\
\text { Factor }\end{array}$ & $\begin{array}{l}\text { PASA } \\
\text { Factor }\end{array}$ \\
\hline$\Gamma$ & $\frac{\text { Lotus }}{\text { Team }}$ & KB Invisible exams 1 & 10-1.:ау-2004 2:05 PM & 80 & View & Matrix \\
\hline$\Gamma$ & $\begin{array}{l}\text { Wing } \\
\text { Lam }\end{array}$ & \multicolumn{2}{|c|}{- do- } & 82 & 1.02 & 0.61 \\
\hline$\Gamma$ & Lily Koh & \multicolumn{2}{|c|}{-do- } & 90 & 1.12 & 1.00 \\
\hline$\Gamma$ & $\begin{array}{l}\text { Arjun } \\
\text { Singh }\end{array}$ & \multicolumn{2}{|c|}{-do- } & 66 & 0.83 & 0.58 \\
\hline
\end{tabular}

Figure 2. SPA and PASA factors

A useful way of thinking about this is to look upon the team score as a cake. If someone is adjudged - by the team as a whole - to have contributed more to a team assignment (qualitatively and quantitatively) compared to other team members then they should be rewarded with a bigger slice of the cake. Note well, however, that in making such a judgement, the other team members are settling for smaller slices of the cake. The size of the cake does not change.

\section{The PASA factor}

While the peer assessment system is automated, SPA-adjusted individual scores for team assignments are not automatically published. Before publication, faculty have the opportunity to moderate individual scores. In conducting this moderation process, they have access to a matrix where they can see the scores that students have awarded one another. Faculty are also provided with information on how individual team members have assessed their peers' contributions relative to how these individuals have assessed their own contribution. This ratio is the PASA factor (Peer Assessment-Self Assessment factor).

If a learner has a PASA factor of 1.0, this implies that their peers' evaluation of their contribution is the same as their own evaluation. If, on the other hand, they have a PASA factor of 0.61, they have over-estimated the worth of their own contribution to the team effort relative to their peers' assessment of their contribution (i.e. PA/SA < 1) (see Figure 2). Correspondingly, if a learner has 
a PASA factor greater than 1 (i.e. PA/SA $>1$ ), they have under-estimated the worth of their own contribution to the team effort relative to their peers' assessment of their contribution. It is difficult, therefore, for an individual to benefit from being overly generous in their assessment of their own contributions.

\section{Team functionality}

If a team functions well, and each member of the team makes a roughly equal contribution, then each team member's SPA factor will be 1.0, and the impact of peer assessment on a student's individual score for a team assignment will be neutral; that is, they will receive the team score $\times 1.0=$ team score. The very existence of a peer assessment system makes this outcome more likely as potential 'free riders' will know that they have to be good 'team players' or they will lose out. It is possible for someone to earn themselves a significant increase in their individual score over the team score but only to the extent that other team members are collectively prepared to grant this increase. The 'cake' does not grow in size - it is just a question of how it is sliced.

Aside from the moral and ethical considerations of ensuring that each team member is rewarded appropriately for their input to a team assignment, reflecting on one's own contributions and their relative worth is an important part of the learning process. It compels the learner to think deeply about the strategy they will employ in preparing team assignments in the future.

\section{Overview of early experience and future plans}

After twelve months' experience with the mandatory peer assessment system for team assignments, the full-time faculty at U21G consider it to be a modest success. There were a lot of teething problems to begin with, largely because students were not attuned to the fact that they only had three days to submit their peer assessments after submitting the team assignment. Meanwhile, some adjunct faculty simply failed to understand how the system worked, and this generated more confusion. With the benefit of hindsight, there should have been a pilot of the new initiative before launching it more broadly. Drawing on the experience of UTS was clearly not enough and a lot more public information and faculty training needed to be put in place. These issues aside, the complaints about free-riders has dried up to a trickle, and after tweaking the system here and there, it is now functioning smoothly.

A formal evaluation of the peer assessment system is currently underway which is expected to generate a number of research questions. Among them is the extent to which the system has enhanced team functionality over time, as learners become familiar with its outcomes, and change their behaviour accordingly. Hypothetically, one would expect teams to become less dysfunctional as they proceed through a subject, and from subject to subject through a degree programme. 


\section{References}

Cheng, W. \& Warren, M. (2000), 'Making a difference: using peers to assess individual students' contributions to a group project', Teaching in Higher Education, 5(2), 243-255.

Conway, R., Kember, D., Sivan, A. \& Wu, M. (1993), 'Peer assessment of an individual's contribution to a group work project', Assessment and Evaluation in Higher Education, 18(1), 45-56.

Freeman M. \& McKenzie J. (2002), 'SPARK, a confidential web-based template for self and peer assessment of student teamwork: Benefits of evaluating across different subjects', British Journal of Educational Technology, 33(5), 551-569.

Goldfinch, J. (1994), 'Further developments in peer assessment of group projects', Assessment and Evaluation in Higher Education, 19(1), 29-35.

Kadel, S. \& Keehner, J.A. (1994), Collaborative Learning: A Sourcebook for Higher Education, Vol. II. University Park, PA: National Center for Postsecondary Teaching, Learning and Assessment.

Lejk, M., Wyvill, M. \& Farrow, S. (1996), 'A survey of methods of deriving individual grades from group assessments', Assessment and Evaluation in Higher Education, 21(3), 267-280.

Pitt, M. J. (2000), 'The application of games theory to group project assessment', Teaching in Higher Education, 5(2), 233-241.

Senge, P. (1990), The Fifth Discipline, London: Century Business. 